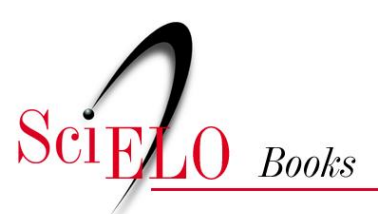

\title{
Metodologias de coleta e conservação
}

\author{
Thereza de Almeida Garbelotto \\ Luiz Alexandre Campos
}

\section{SciELO Books / SciELO Livros / SciELO Libros}

GARBELOTTO, TA., and CAMPOS, LA. Metodologias de coleta e conservação. In: Pentatominae do Sul de Santa Catarina [online]. Curitiba: Sociedade Brasileira de Zoologia, 2014, pp. 77-78.

Zoologia: guias e manuais de identificação series. ISBN 978-85-98203-08-9. Available from SciELO Books $<$ http://books.scielo.org $>$.

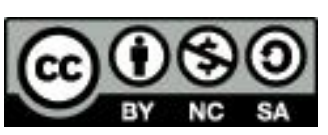

All the contents of this chapter, except where otherwise noted, is licensed under a Creative Commons Attribution-Non Commercial-ShareAlike 3.0 Unported.

Todo o conteúdo deste capítulo, exceto quando houver ressalva, é publicado sob a licença Creative Commons Atribuição Uso Não Comercial - Partilha nos Mesmos Termos 3.0 Não adaptada.

Todo el contenido de este capítulo, excepto donde se indique lo contrario, está bajo licencia de la licencia Creative Commons Reconocimento-NoComercial-CompartirIgual 3.0 Unported. 


\section{Metodologias de coleta e conservação}

A maneira mais fácil de coletar percevejos é manualmente, porém assim ficamos restritos a coletá-los apenas quando os vemos sobre a vegetação. Existem diferentes métodos de coleta de insetos, dentre os quais os mais utilizados para coleta de percevejos são descritos a seguir.

Guarda-chuva entomológico: utilizado para a coleta de insetos que pousam em arbustos. É feito basicamente com um quadrado de tecido, preferencialmente branco, com reforços triangulares nos cantos onde serão encaixadas as pontas das varas intercruzadas (Fig. 3). Um bastão é necessário para bater nos arbustos, fazendo com que os insetos caiam sobre o guarda-chuva. Depois de caírem no guarda-chuva, os insetos são capturados e armazenados em potes plásticos.

Rede de varredura: é utilizada para coletar insetos que vivem na vegetação rasteira. Tem uma estrutura similar às 'redes entomológicas' que são utilizadas para capturar insetos durante o voo (como borboletas e abelhas), mas a rede de varredura é usada para bater na folhagem como se estivesse "varrendo" toda a fauna de insetos que se encontra ali.

A rede é feita de um tecido resistente costurado em forma de saco com uma borda por onde passará um aro de arame também resistente (é aconselhado que a borda seja reforçada com lona ou tecido duplo) preso a um cabo de madeira (Fig. 4). O tecido deve ser grosso para resistir aos danos, como perfurações, que os ramos de plantas poderiam causar à rede.

Todo o material coletado é recolhido em sacos plásticos contendo um chumaço de algodão embebido em acetato de etila e levado ao laboratório para triagem.

Armadilha luminosa: existem diferentes tipos de armadilha que utilizam a luz como atrativo para coletar insetos. Pode-se utilizar um pedaço de tecido branco esticado entre dois suportes (como um lençol), ou uma parede como área de coleta, iluminada por uma fonte de luz. O coletor fica por perto e coleta os insetos do grupo alvo que são atraídos.

Um outro tipo comum de armadilha luminosa é o modelo "Luiz de Queiroz" que consiste de um funil de alumínio que se encaixa a uma armação feita com quatro aletas de alumínio, montadas cruzadas ao redor de uma lâmpada fluorescente. Na parte inferior da armadilha, um pote com álcool $70 \%$ para aprisionar ou matar os insetos. A armadilha tem ainda um disco de alumínio sobre as aletas para proteção da água da chuva (Fig. 4). No centro deste disco, é colocada uma alça por onde a armadilha será suspensa entre a vegetação.

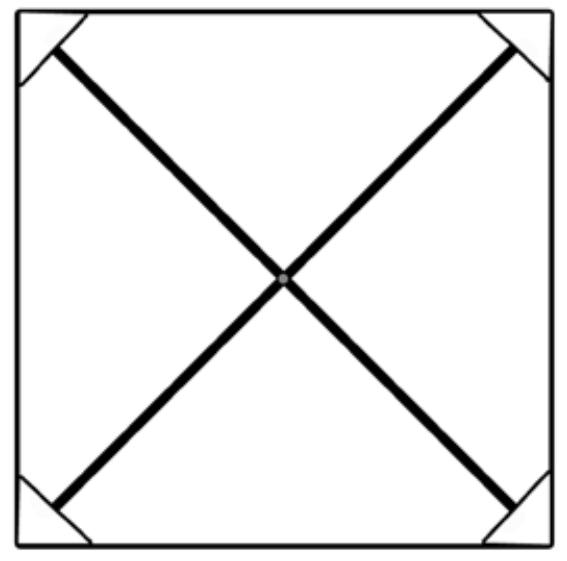

Figura 3: Representação esquemática de um guardachuva entomológico.

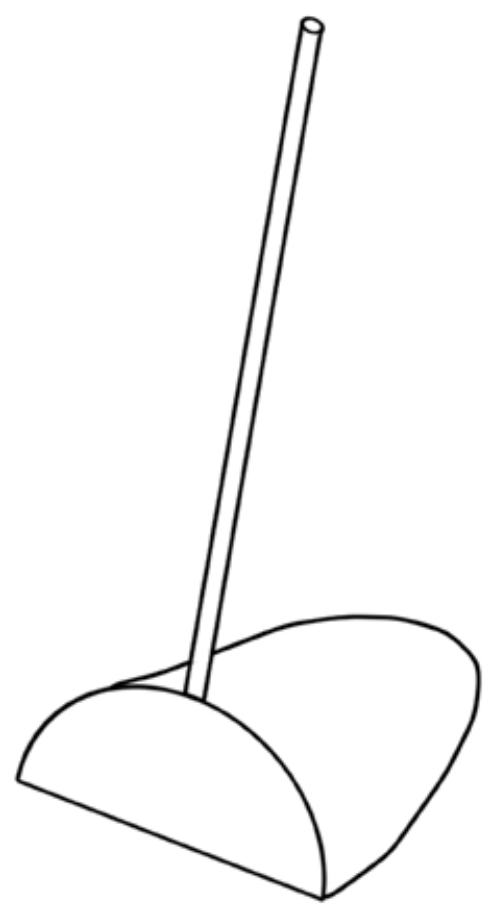

Figura 4: Representação esquemática de uma rede de varredura. 
Após a coleta, os insetos precisam ser montados e conservados de maneira adequada para trabalhos posteriores. No caso dos percevejos dois meios de conservação são mais utilizados: via líquida, com a conservação em álcool 70\%, ou a seco com o uso de alfinetes entomológicos.

Para conservação a seco, deve-se alfinetar os percevejos e secá-los em estufa para posterior armazenamento em caixas entomológicas. Para a montagem insira o alfinete no escutelo com um deslocamento à direita da linha mediana do corpo (Fig. 6), perfure o inseto até posicioná-lo entre o centro e a cabeça do alfinete, ou a cerca de $1,5 \mathrm{~cm}$ abaixo da cabeça do alfinete. Pode-se usar blocos com perfurações para ajuste da altura do exemplar no alfinete. Posicione as pernas e antenas adequadamente, leve o material à estufa e quando seco armazene em caixa entomológicas. Todo o material deve ser etiquetado com as informações de coleta (local, data, coletor) em etiquetas de aproximadamente $2 \times 2 \mathrm{~cm}$.

Para mais informações sobre estes e outros métodos de coleta e conservação de insetos veja os seguintes livros:

- Insetos do Brasil: Diversidade e Taxonomia - Rafael, J.A.; Melo, G.A.R.; Carvalho, C.J.B; Casari, S.A. \& Constantino, R. - Holos Editora (2012).

- Estudo dos insetos - Triplehorn, C.A \& Jonnson, N.F. - Cengage Learning (2011)

- Manual de coleta, conservação, montagem e identificação de insetos - Almeida, L.M.; Ribeiro-Costa, C.S. \& Marinoni, L. - Holos Editora (1998).

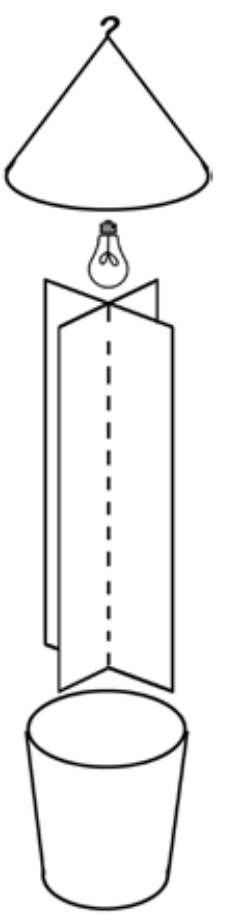

Figura 5: Representação esquemática de uma armadilha luminosa.

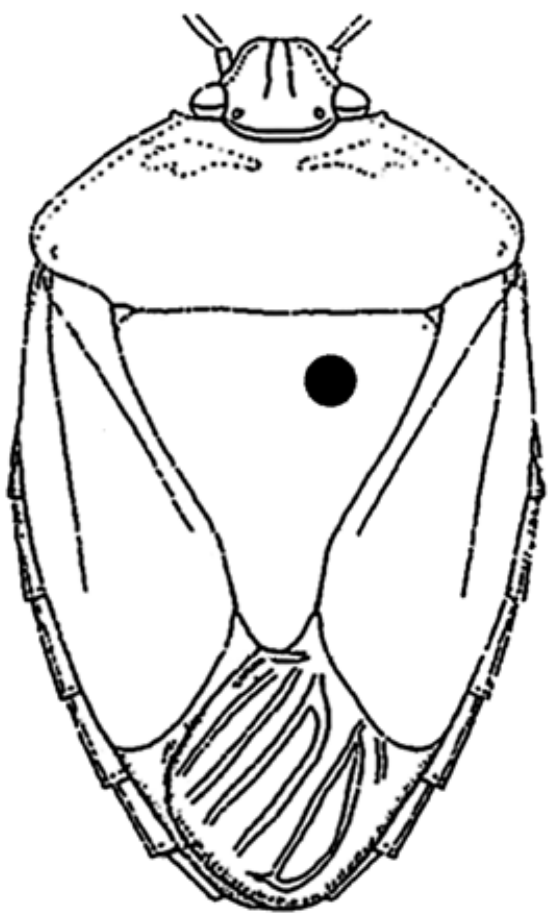

Figura 6: Indicação da posição correta para inserir o alfinete em um pentatomídeo. 